\title{
A pesquisa e a integração universidade e ensino médio
}

\section{The research and the integration university - high school}

\section{Resumo}

Este artigo tem como objetivo apresentar a experiência de implantação do Programa de Iniciação Científica Júnior, do Centro Universitário de Brasília (UniCEUB), destacando a importância da pesquisa e da integração universidade e ensino médio nos aspectos da prática científica dos alunos e da articulação desses dois níveis de ensino. Ressalta-se a concepção do Programa, no que se refere ao papel pedagógico da pesquisa, como elemento formador de habilidades iniciais ao processo de pesquisa e suas contribuições no preparo do aluno para a vida profissional e para o ingresso na universidade.

Palavras-chave: Iniciação Científica Júnior. Pesquisa. Ensino médio. Integração. Universidade.

\begin{abstract}
This paper aims to present the experience of implementing the Program of Junior Scientific Initiation, of the University Center of Brasilia, highlighting the importance of research and the integration between the university and the high school in the aspects of the students' scientific practice and the articulation between these two levels of education. It is highlighted the design of the program, with regard to the pedagogical role of the research as an element which builds initial skills to the process of research and its contributions in preparing the student for the professional life and for university entrance.
\end{abstract}

Keywords: Junior Scientific Initiation. Research. High school. Integration. University 


\section{Introdução}

O presente artigo trata da iniciação científica no ensino médio vista como uma experiência enriquecedora para professores e para alunos. Tem como objetivo difundir a experiência de integração entre universidade e ensino médio, em especial, sinalizar práticas pedagógicas que privilegiem o diálogo e a cooperação interinstitucional na esfera acadêmica.

A metodologia utilizada para desenvolver este artigo constou de levantamento de dados institucionais sobre o Programa, enfatizando as instituições participantes, a forma de ingresso no Programa e as contribuições em nível acadêmico e institucional. Foi feita uma revisão da literatura sobre a iniciação científica, destacando a concepção do programa.

A pesquisa é uma condição necessária ao processo de ensino, de aprendizagem e de produção de conhecimentos nas instituições universitárias e tem como função essencial estar integrada ao ensino e à extensão. É da natureza da universidade desenvolver o processo de pesquisa e de produção de conhecimentos, conforme preconiza a Lei de Diretrizes e Bases da Educação Nacional (LDB) no seu art. $43^{\circ}$ inciso III. Segundo $\mathrm{aDB}$, cabe à universidade

Incentivar o trabalho de pesquisa e investigação científica, visando o desenvolvimento da ciência e da tecnologia e da criação e difusão da cultura, e, desse modo, desenvolver o entendimento do homem e do meio em que vive. (BRASIL, 1996)

A pesquisa, como produção de conhecimento no ensino médio, é uma prática pouco utilizada por professores e alunos e isso tem implicações tanto na forma de aprendizagem, como na relação do aluno com a vida profissional e com a universidade. Na universidade, a sua adaptação pode ser mais difícil, considerando as novas metodologias de ensino utilizadas com base na multidisciplinaridade e na relação ensino-pesquisa.

Essa questão tem recebido uma atenção especial do Conselho Nacional de Desenvolvimento Científico e Tecnológico (CNPq) e de algumas fundações estaduais de pesquisa, os quais criaram programas de Iniciação Científica Júnior, buscando incentivar e apoiar as iniciativas de pesquisa.

O Programa instituído pelo CNPq tem como objetivo despertar a vocação científica e incentivar talentos potenciais entre estudantes dos ensinos fundamental, médio e profissional da rede pública, mediante sua participação em atividades de pesquisa científica ou tecnológica, orientadas por pesquisadores qualificados, em instituições de ensino superior ou institutos/centros de pesquisas (BRASIL, 2006). O CNPq concede quotas de bolsas, na modalidade Iniciação Científica Júnior, às entidades estaduais de fomento à pesquisa, fundações de amparo ou secretarias estaduais (FAPS) e outras instituições, por meio de acordo de cooperação técnica, sem repasse de recursos, ou por convênio com repasse. Cabe à FAPS divulgar os editais e receber as propostas de pesquisa.

\section{Concepção e prática do Programa de Inicia- ção Científica Júnior no UniCEUB}

Seguindo a Política Nacional de Incentivo à Iniciação Científica Júnior, o UniCEUB criou o Programa de acordo com as diretrizes do CNPq. Constitui-se em um Programa de apoio à pesquisa e de integração dos alunos do ensino médio às atividades técnico-científicas. O Programa busca inserir o aluno na prática da pesquisa por meio da orientação e do acompanhamento de um professor orientador, tendo como objetivos: estimular os alunos do ensino médio a desenvolverem pesquisa; despertar a vocação científica e incentivar o intercâmbio de pesquisa entre alunos do ensino médio da rede pública e privada do Distrito Federal; introduzir e disseminar a pesquisa, possibilitando maior articulação entre o ensino médio e a graduação; e estimular o interesse do aluno pela atividade de pesquisa. Tal experiência permite um diálogo integrador entre as duas instâncias - universidade e instituições de ensino médio, entre alunos e professores. Uma premissa norteadora dessa prática é a de que a pesquisa pode ser realizada por um grupo integrado, disposto a pensar cientificamente sobre questões, problemas e temas, os quais merecem ser transformados em objeto de pesquisa com a participação de alunos do ensino médio.

Esta prática pedagógica institucional centrada na relação do grupo contribui para o ensino/pesquisa e cria um ambiente científico que permite integrar teoria e prática. Além disso, substitui um saber fechado e reprodutivo por um conhecimento aberto e dinâmico, sinalizado por práticas pedagógicas que priorizam o conhecimento de forma reconstrutiva e interativa. O Programa de Iniciação Científica permite ainda o desenvolvimento de ações pedagógicas centradas na pesquisa. Esse enfoque 
de pesquisa interligada à ação pedagógica pressupõe uma nova dimensão da atividade de ensino/pesquisa - o desenvolvimento de práticas interativas e colaborativas.

Assim, pode-se dizer que tal prática é, antes de tudo, uma pedagogia da ação. Dessa forma, estará inserida em uma dupla perspectiva - a educação, entendida como processo educativo e como integração do fazer científico. Tais pressupostos encaminham para a relação pedagógica construída por vários atores científicos pela possibilidade de integração teoria/prática, e para a compreensão da pesquisa como uma atividade criativa e crítica de produção de conhecimentos. Desse processo, deve resultar a compreensão do fazer científico, da prática interdisciplinar, da articulação teoria/prática e do aprender integrado pesquisa/ensino no processo de produção de conhecimento. Nesse sentido, os orientadores exercem a dupla ação pedagógica: a de ensinar e a de pesquisar, a de aprender e a de ensinar, nas quais, na visão de Bachelard (2000), o professor realiza a sua verdadeira função de educador.

Nessa perspectiva, o Programa de Iniciação Científica cumpre essa premissa de fortalecimento da vocação científica. Apresenta um caráter multidisciplinar, considerando que o aluno sai do foco da sala de aula para o foco externo multidisciplinar, o que amplia a sua visão e permite que ele estabeleça diálogos com o mundo real.

A autoria e autonomia são palavras decisivas nos processos formativos dos indivíduos educados cientificamente, visto que a elaboração de conhecimento inovador é o ponto "chave" para o desenvolvimento de uma sociedade e a pesquisa é, a nosso ver, a melhor forma de alcançá-lo (PEREIRA; PEREIRA; NASCIMENTO, 2011, p. 6142).

No entanto, para pensar o ensino com base na pesquisa, é necessário reverter a lógica do ensino tradicional, na qual todo o processo está centrado no professor e na sala de aula. Na lógica da pesquisa, o aluno é o centro da ação pedagógica, e a universidade pode contribuir com esse processo. $\mathrm{O}$ aluno é instigado a pensar e a formular uma pergunta, base de pesquisa. Em conjunto com o professor, as questões vão sendo construídas cientificamente até a produção do conhecimento, com base em referenciais teóricos e metodológicos adequados à proposta inicial ensejada no objeto /tema de estudo.

Esse processo contribui para desenvolver a autonomia intelectual do aluno tornando-o um sujeito com atitudes questionadoras na sua vida acadêmica, profissional e prática.

Essa pedagogia busca intensificar a qualidade do ensino e das práticas de pesquisa, fortalecendo a integração universidade e ensino médio. A relação qualidade/ ensino e pesquisa encontra no Programa de Iniciação Científica Júnior um instrumento importante no qual o aluno tem a oportunidade de desenvolver experiências centradas na capacidade de construir problemas de pesquisa adequados ao nível do ensino médio.

Essa prática científica rompe com o ensino meramente instrumental e fortalece a dimensão da atividade científica centrada no ensino/pesquisa e na pesquisa/ensino. Pedagogicamente, realiza uma formação integrada que propicia ao aluno o desenvolvimento de sua iniciação científica, capacitando-o para interagir com realidades complexas e com situações-problema no campo científico. $\mathrm{O}$ aluno que vivencia essa experiência com base nessa pedagogia terá um perfil diferenciado em sua vida profissional e sua adaptação na universidade será mais fácil.

Em parceria com as instituições de ensino médio, o UniCEUB desenvolveu pesquisas em várias áreas do conhecimento, realizando a sua função de ensino e pesquisa. Nesse sentido, a prática de iniciação científica implementada pelo UniCEUB auxilia as instituições de ensino médio a produzirem conhecimento e a interagirem com a universidade.

O processo de iniciação científica possibilitou o desenvolvimento de pesquisas institucionalizadas. $\mathrm{O}$ corpo docente envolvido, por sua vez, teve a oportunidade de fortalecer seus temas de pesquisas, aprofundando novas temáticas. Tal prática propicia o desenvolvimento da docência articulada à pesquisa. Noutra direção, contribuiu para que o professor pudesse incorporar ao seu campo de pesquisa novos interesses e temas provenientes dos alunos.

A articulação entre a Universidade e o Ensino Médio, seja na formação docente quanto na formação profissional e cidadã do aluno, contribui para a redução das deficiências que os ingressantes da educação superior apresentam, bem como, desperta para as vocações científicas e tecnológicas (PEREIRA; PEREIRA; NASCIMENTO, 2011, p. 6148).

A prática da pesquisa possibilita à instituição e ao corpo docente e discente estabelecer rupturas com a dimensão puramente disciplinar em direção à perspectiva 
multidisciplinar. Nesse sentido, as equipes de pesquisa apreendem a complexidade dos problemas, desenvolvendo novas referências de análise. Por outro lado, a pesquisa constitui-se em suporte ao ensino na medida em que os objetivos do ensino médio se ampliam e se aprofundam. Dessa forma, a pesquisa, já no ensino médio, deve ser uma preocupação dos docentes como suporte à dimensão de ensino.

Para o desenvolvimento do Programa, foram criados mecanismos de gestão pedagógica, que formam um processo institucional e educacional de incentivo à prática e à cultura científica entre alunos e professores. Procurou-se fortalecer e estimular um ambiente acadêmico de ações formativas, com orientação no processo de pesquisa, elaboração de projeto e uso de recursos da biblioteca. O Programa foi implementado mediante a publicação de editais, nos quais os referenciais e as normas foram divulgados à comunidade acadêmica em parceria com os colégios que a integram.

Durante todo o processo, a gestão pedagógica foi realizada mediante ações de apoio, acompanhamento e promoção de cursos de extensão. $\mathrm{O}$ apoio ao aluno foi realizado pela coordenação do Programa, que procurou esclarecer e sanar todas as dúvidas referentes a ele e fazer o acompanhamento durante o período de duração da pesquisa, mediante reuniões com alunos e orientadores. Nas reuniões, procurou-se identificar possíveis dificuldades encontradas por alunos e professores e propor formas de resolvê-las.

No processo de avaliação dos centros universitários, um dos itens componentes da avaliação é a produção científica, tecnológica e cultural. Nesse sentido, o Programa de Iniciação Científica é um fortalecedor dessa produção, articulado ao ensino médio.

Assim, o aluno terá a oportunidade de ser formado com base na perspectiva investigativa e poderá ser um sujeito mais aberto, flexível, solidário, democrático e crítico. Será motivado, desse modo, à curiosidade e a novas descobertas. Tais experiências contribuem para os professores vivenciarem novas maneiras de ensinar, rompendo com o ensino centrado somente na sala de aula. $\mathrm{O}$ Programa contribuiu para reforçar a afirmação de Paulo Freire de que o ensinar exige pesquisa.

Não há ensino sem pesquisa e pesquisa sem ensino. Esses que-fazeres se encontram um no corpo do outro. Enquanto ensino, continuo o buscando, reprocurando. Ensino porque busco, porque indaguei, porque indago e me indago. Pesquiso para constatar, constatando, intervenho, intervindo educo e me educo. Pesquiso para conhecer o que ainda não conheço e comunicar ou anunciar a novidade (FREIRE, 1996, p. 29).

A educação científica é uma tarefa conjunta do ensino médio e da universidade. Para Demo (2010, p. 1516), a educação científica constitui uma das habilidades do século XXI por ser este século marcado "pela sociedade intensiva de conhecimento". O desafio da sociedade contemporânea é produzir conhecimento e não somente absorver conteúdos. Para isso, é necessário investir neste processo, que pode apresentar alguma originalidade com relação à divulgação dos resultados das pesquisas desenvolvidas em diversas áreas do conhecimento. O UniCEUB apresenta, anualmente, os resultados no Encontro de Iniciação Científica na forma de comunicação de pesquisa. O Programa de Iniciação Científica teve início em 2007 e o UniCEUB foi a primeira instituição do Distrito Federal a ter essa iniciativa. Durante os anos de 2004 até 2012 foram implantados e desenvolvidos 50 projetos de iniciação científica, envolvendo escolas públicas e privadas.

$\mathrm{Na}$ avaliação dos alunos, a experiência é muito importante porque eles aprendem os primeiros passos da pesquisa, com o apoio e a orientação dos professores. Segundo os alunos, foi possível entender como se faz uma pesquisa. Eles conseguiram fazer as leituras, realizar o levantamento de dados e concluir a pesquisa, apresentando os seus resultados. Com isso, sentiram-se mais seguros e valorizados.

Quadro 1 - Programa de Iniciação Científica Júnior - PIC Júnior

\begin{tabular}{|c|c|}
\hline $\begin{array}{c}\text { Modalidade de bolsas e de } \\
\text { ingresso }\end{array}$ & $\begin{array}{c}\text { Número de projetos } \\
\text { desenvolvidos }\end{array}$ \\
\hline FAP & 23 \\
\hline UniCEUB & 18 \\
\hline Voluntário & 09 \\
\hline Total & 50 \\
\hline
\end{tabular}

Fonte: Dados da Assessoria de Pesquisa e Pós-graduação do UniCEUB.

Dos projetos, 23 tiveram bolsas da Fundação de Apoio à Pesquisa- FAP/DF, 18 tiveram bolsas concedidas pelo UniCEUB, e 9 foram desenvolvidos de forma voluntária. A seguir estão listados parte dos projetos aprovados e desenvolvidos.

Os projetos de pesquisa desenvolvidos por professores e alunos do Colégio CEUB (hoje já extinto) tiveram como temas de pesquisa: 
- Preservação das plantas que salvam vidas;

- Proposta de implantação de programa de gerenciamento de resíduos químicos no âmbito do laboratório multidisciplinar de ensino do UniCEUB - Labocien;

- Percepção de alunos do ensino médio em relação ao papel ecológico dos insetos no processo de decomposição;

- Estudo comparativo de óleos essenciais extraídos das cascas de frutas cítricas obtidas por micro-propagação em condições usuais;

- Making off na escola: a produção de curta-metragem com possibilidade pedagógica no ensino de inglês e da educação artística no ensino médio;

- Aves no campus do UniCEUB;

- Resgate cultural e geração de emprego e renda por meio da fitoterapia;

- Revisão da literatura sobre as plantas do gênero Beuhinia (Pata de Vaca);

- Alimentação alternativa;

- Estudo do impacto gerado no meio ambiente pela utilização de combustíveis derivados do petróleo;

- Lazer e educação: um estudo sobre o Programa Escola aberto na cidade do Itapoã/DF;

- Avaliação do consumo máximo de oxigênio e da hipotensão pós-exercício em indivíduos normotensos em esteira ergométrica;

- O cinema nas aulas de educação física: uma proposta de ação pedagógica no ensino médio;

- Análise da herbivoria em um fragmento urbano de cerrado como ferramenta de aprendizagem significativa.

Os projetos do Colégio Gisno se centraram nos seguintes temas de pesquisa:

- Conhecendo o Supremo Tribunal Federal: a prática da pedagogia constitucional para alunos do ensino médio;
- Políticas migratórias: uma análise comparativa Espanha X Estados Unidos

- Biologia de coruja suidara (Tyto alba) e coruja buraqueira (Athene cunicularia) do campus do UniCEUB e Gisno: identificação de fauna e formação de uma coleção didática;

- Papel ecológico dos insetos no processo de decomposição de matéria orgânica.

No Colégio Leonardo da Vinci, os alunos tiveram como temas:

- Projeto Ecovinci: construindo a consciência da sustentabilidade;

- Planejamento urbano versus especulação imobiliária: um estudo de caso de Águas Claras - RA XX;

- O uso das redes sociais como forma de expressão política;

- Um estudo de caso dos espaços urbanos públicos de lazer do Varjão - RA XXIII;

- As redes sociais como espaço para a sociabilidade e a manifestação política jovem;

- Produção do etanol a partir do caldo de cana, do bagaço e da casca do eucalipto;

- Sustentabilidade na Escola: produção de horta vertical em laboratório de ensino médio;

- Educação ambiental: produção de compostagem microbiológica e de minhocário em laboratório de ensino médio. Energia solar para a sustentabilidade de uma sala de aula.

No Colégio Marista, os alunos tiveram como temas:

- Geografia, ecologia, zoologia: sistemática e evolução;

- O uso de tablets no processo de ensino/ aprendizagem de ciências da natureza no ensino médio;

- A ressignificação da vida por meio da educação de jovens e adultos. 
Quadro 2 - Relação dos colégios participantes do Programa por ano, número de alunos e número de orientadores.

\begin{tabular}{|c|c|c|c|}
\hline Colégio & Ano & $\begin{array}{c}\text { Número de } \\
\text { alunos }\end{array}$ & $\begin{array}{c}\text { Número de } \\
\text { orientadores }\end{array}$ \\
\hline Colégio CEUB & 2008 & 05 & 05 \\
\hline Colégio CEUB & 2009 & 06 & 06 \\
\hline $\begin{array}{c}\text { Centro de } \\
\text { Ensino Médio } \\
\text { da Asa Norte }\end{array}$ & 2009 & 03 & 01 \\
\hline $\begin{array}{c}\text { Centro de } \\
\text { Ensino Médio } \\
\text { do Gama }{ }^{*}\end{array}$ & 2009 & 02 & 01 \\
\hline $\begin{array}{c}\text { Centro } \\
\text { Educacional } \\
\text { Gisno }\end{array}$ & 2009 & 21 & 09 \\
\hline Colégio CEUB & 2010 & 06 & 03 \\
\hline $\begin{array}{c}\text { Colégio } \\
\text { Leonardo da } \\
\text { Vinci }\end{array}$ & 2011 & 36 & 15 \\
\hline Colégio Marista & 2012 & 11 & 10 \\
\hline Total: & & $\mathbf{1 2 0}$ & $\mathbf{5 0}$ \\
\hline
\end{tabular}

Fonte: Dados da Assessoria de Pesquisa e Pós-graduação do UniCEUB.

O Programa desenvolveu-se em três modalidades: bolsa da FAP/DF, bolsa do UniCEUB e de forma voluntária.

Quadro 3 - Projetos desenvolvidos: forma de apoio e de ingresso.

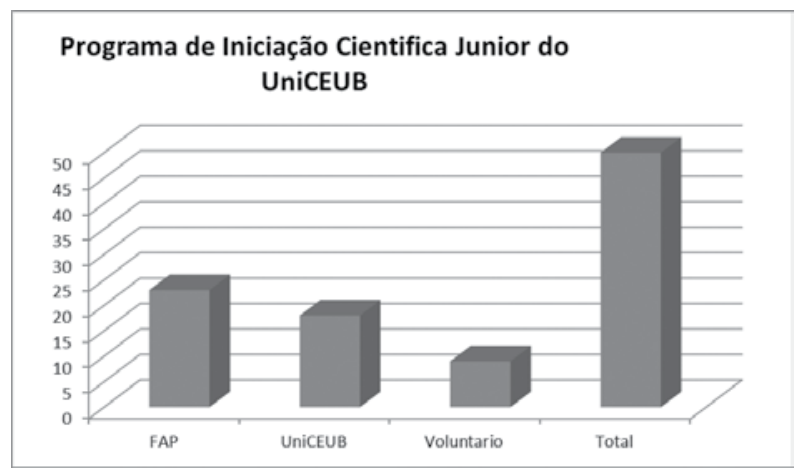

Fonte: Dados da Assessoria de Pesquisa e Pós-graduação do UniCEUB.

Em 2012, o Programa teve a sua estratégia ampliada. Contou com um coorientador do UniCEUB e um professor do colégio participante do Programa, orientando diretamente os alunos em uma cooperação tridimensional. Essa metodologia permitiu criar equipes integradas de pesquisa.
Figura 1 - Matriz Tridimensional de integração do processo de orientação do Programa PIC/Júnior

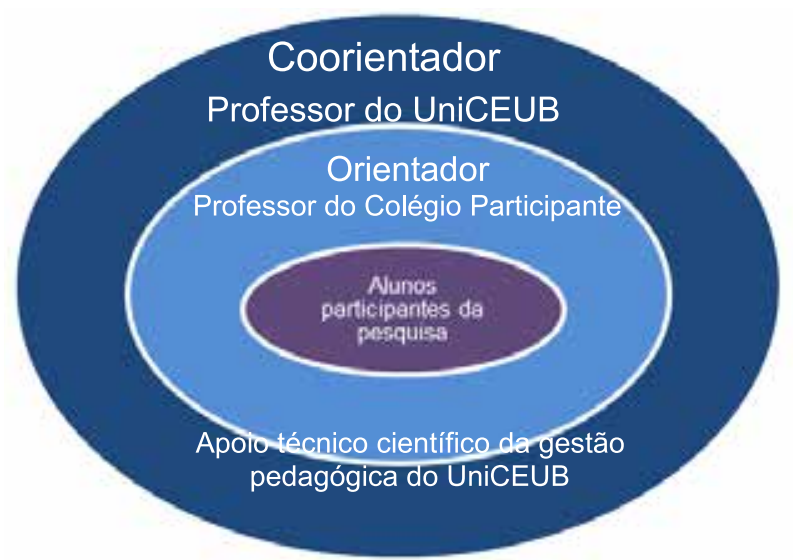

Fonte: Elaboração da autora.

\section{Considerações finais}

No que se refere à integração universidade e ensino médio, o Programa de Iniciação Cientifica Júnior vem preencher um espaço até então pouco explorado, levando esse nível de experiência ao ensino médio a partir da colaboração da universidade no desenvolvimento de projetos integrados de pesquisa. As principais contribuições desse processo são: o aluno teria a oportunidade de desenvolver o senso de busca e a disciplina para o trabalho de pesquisa; aprenderia as bases iniciais desse estudo, o que facilitaria o processo de integração com o ensino superior; os professores poderiam desenvolver seus temas de pesquisa com novas formas de ensino que gerariam processos interdisciplinares de produção e conhecimento, e não apenas de reprodução. Nesse sentido, alunos e professores se reconheceriam como sujeitos ativos, colocando problemas de pesquisa e buscando analisá-los e interpretá-los de acordo com os pressupostos da pesquisa científica. Isso implicaria desenvolvimento de talentos para a pesquisa já no ensino médio, preparando o aluno para desafios dos novos níveis de ensino, especialmente o universitário.

\section{Referências}

BACHELARD, Gaston. O novo espírito científico. Rio de Janeiro: Tempo Brasileiro, 2000.

BRASIL. Conselho Nacional de Pesquisa. Fixa requisitos, condições, benefícios e orientações necessárias à implementação das bolsas de Iniciação Científica Júnior. Brasília: CNPq, IS010, 2006. 
BRASIL. Lei n. 9.394, de 20 de dezembro 1996. Estabelece as Diretrizes e Bases da Educação Nacional. Diário Oficial [da] República Federativa do Brasil. Brasília, DF, 23 dez. 1996. Seção 1. Disponível em <http://portal.mec.gov.br/ arquivos/pdf/ldb.pdf $>$ Acesso em: 08 ago. 2012.

DEMO, Pedro. Educação científica. B. Téc. Senac: a R. Educ. Prof., Rio de Janeiro, v. 36, n. 1, p. 15-15, jan./abr. 2010. Disponível em: <www.senac.br/BTS/361artigo2. pdf >. Acesso em: 10 set. 2012.

FONSECA, Dirce Mendes. Documento Orientado do Programa de Iniciação Científica Júnior. Brasília: UniCEUB, 2012.
FONSECA, Dirce Mendes. Programa de Iniciação Científica: PIC UniCEUB - orientações gerais. Brasília: UniCEUB, 2007.

FREIRE, Paulo. Pedagogia da autonomia: saberes necessários à prática educativa. São Paulo: Paz e Terra, 1996.

PEREIRA, Inaiá Brandão; PEREIRA, Tania Regina D. S.; NASCIMENTO, Fabiana dos Santos. Articulação universidade e ensino médio: potencialidades das geotecnologias e o conhecimento científico. In: CONGRESSO NACIONAL DE EDUCAÇÃO, 10, 2011, Curitiba. Anais... Curitiba, 2011, p. 6138-6150. 


\section{Para publicar na revista}

Universitas Humanas,

acesse $o$ endereço eletrônico www.publicacoesacademicas.uniceub.br. Observe as normas de publicação, para facilitar e agilizar o trabalho de edição. 